\title{
DISCLAIMER
}

This report was prepared as an account of work sponsored by an agency of the United States Government. Neither the United States Government nor any agency thereof, nor any of their employees, makes any warranty, express or implied, or assumes any legal liability or responsibility for the accuracy, completeness, or usefulness of any information, apparatus, product, or process disclosed, or represents that its use would not infringe privately owned rights. Reference herein to any specific commercial product, process, or service by trade name, trademark. manufacturer, or otherwise does not necessarily constitute or imply its endorsement, recommendation, or favoring by the United States Government or any agency thereof. The views and opinions of authors expressed herein do not necessarily state or reflect those of the United States Government or any agency thereof.

\section{A USER'S GUIDE TO PARTICLE PHYSICS COMPUTER-SEARCHABLE DATABASES ON THE SLAC-SPIRES SYSTEM}

\section{Particle Data Group}

A. Rittenberg, F.E. Armstrong, B.S. Levine, T.G. Trippe, C.G. Wohl, and G.P. Yost Laurence Berkeley Laboralory, * University of Californid, Berkeley, CA 94720 USA

M.R. Whalley

Iniversity of Durham, Depl. of Physics, South Rd., Durham City, DH1 SLE, England

L. Addis

Stanford Linear Accelerator Center, P.O. Box 4949 , Stanford, CA 94905 USA

\begin{abstract}
This report discusses five computer-searchable databases located at SLAC which are of interest to particle physicists. These databases assist the user in literature-searching, provide numcrical data extracted from papers, and contain information about experiments. We describe the databases briefly, tell how to use the SPIRES database management system to access them interactively, and give several examples of their use.
\end{abstract}

* The Berkeley Particle Data Group is supported by the Director, Office of Energy Research, Office of High Energy and Nuclear Physics. Division of High Energy Physics of the U.S. Department of Energy under Contract No. DE-ACO9-76SF0009s, and by the U.S. National Science Foundation under Agreemini No. PHY $99-1595.5$. 


\section{A. USER'S GUIDE TO \\ PARTICLE PHYSICS COMPUTER-SEARCHABLE DATABASES ON THE SLAC-SPIRES SYSTEM}

The Berkeley and United Kingdom Particle Data Groups, in collaboration with numerous other groups and institutions, have developed four computer-searchable databases of interest to particle physicists. These databases assist the user in literature-searching, provide numerical data extracted from papers, and contain descriptions of experiments. They thus give much additional information relating to many of the papers contained in the "HEP" database, which has been developed over the years by the SLAC Library and is now maintained by SLAC and DESY. All five of these databases reside on the SLAC IBM 3081 computer and are managed by the SPIRES database management system. In the following sections, we describe the databases briefly, tell how to use SPIRES to access them interactively, and give several examples of their use.

Some of the databases are of long standing and some are new. We hope that you will try to use them and tell us of successes, failures, problems, etc. Suggestions for improving this guide would also be appreciated. Because of the differing histories of the databases, there are unfortunately some inconsistencies among them. We plan eventually to correct most of these.

\section{The Databases}

The figure shows the five databases. HEP and DATAGUIDE are literature-searching guides to

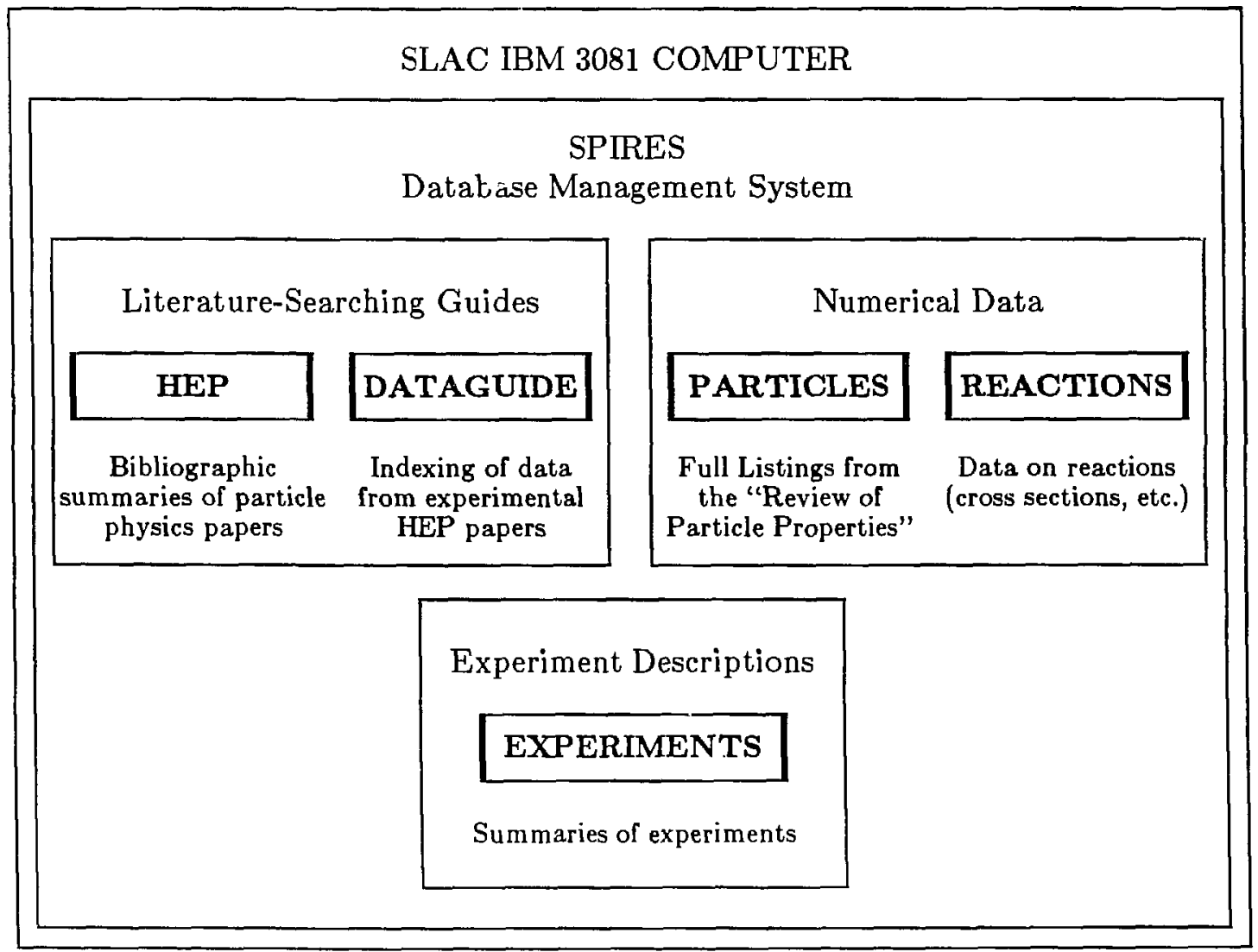


help the user find desired papers; PARTICLES and REAC'TIOAS contain actual numerical data extracted from papers; and EXI'ERIMENTS contains information about experiments.

The description of each database below gives the name by which it is accessed, the type of information it contains, the time period covered, the group responsible for maintenance, the frequency of updating, the kinds of searches which are possible (i.e., the criteria one may use to look for information of interest), and any associated publications.

HEP

DATAGUIDE

PARTICLES

REACTIONS
Contains bibliographic summaries of $\sim 150,000$ particle physics papers (journal articles, preprints, reports, theses, etc., at the ratc of about $15,000 /$ year). Covers 1974 to the present. Maintained by the SLAC Library, in collaboration with the DESY IEP Index Group. Updated daily. Searchable by author, institution, title, topic, report number, citation, etc. The database for the weekly "Preprints in Particles and Fields" (PPF), available from the SLAC Library.

Contains indexing, by type of data reported, of $\sim 10,000$ particle physics papers that contain data. Covers 1976 to the present. Maintained by the Berkeley Particle Data Group (Fi $\bar{i}$ G), in collaboration with the Serpukhov COMPAS Group. Updated weekly. Searchable by reaction, lab momentum, c.m. energy, particle studied, accelerator, detector, and other items. The database for the publication "A Guide to Data in Elementary Particle Physics," LBL-90. ${ }^{1}$

Contains the Full Listings ( $\sim 40,000$ lines of information), but not the Summary Particle Properties Tables, from the "Review of Particle Properties." Covers the same years as the Review. Maintained by the Berkeley PDG, in collaboration with the entire authorship of the Review. Updated approximately every year (once or twice between editions of the Review). Searchable by particle and particle property.

Contains numerical data on reactions from $\sim 2000$ papers; cross sections (differential and total), structure functions, polarization measurements, and many other items from most current aspects of experimental particle pliysics are included. Currently covers 1978 to the present. Compiled by the United Kingdom Particle Data Group (Univ. of Durham and Rutherford Appleton Lab), in collaboration with the Serpukhov COMPAS Group; U.S. distribution by the Berkeley PDG. Updated approximately annually. Searchable by first author, reference, reaction, lab momentum, quantity measured, final state particle.

EXPERIMENTS Contains summaries of $\sim 1200$ approved experiments at the major particle physics labs. Covers approximately 1975 to the present. Maintained by the Berkeley PDG, in collaboration with correspondents at the various labs. Upclated periodically. Searchable by experiment number, author, accelerator, detector, reaction, momentum, journal paper, etc. The database for the publication "Current Experiments in Flementary Particle Physics," L LBL -91.3 


\section{Accessing the Databases}

Anyone who has an account on the SLAC IBM 3081 computer can access these databases. If you have an account but are unfamiliar with SPIRES, a "Guide to VM SPIRES" is available from the SLAC Library, Bin 196, SLAC, P.O. Box 4349, Stanford, CA 94305, USA (phone: 415/854-3300, ext. 2411). If you do not have an account and cannot find anyone who does (at main laboratories, ask at the library), contact Louise Addis of the SLAC Library; you can also get information about using various networks, such as TYMNET, from the same source. If you just want to try out the system, contact us about using a temporary guest account: Particle Data Group, 50-308, Lawrence Berkeley Laboratory, Berkeley, CA 94720 , USA (phone: 415/486-4723, or FTS 451-4723).

In the following description, words not enclosed in angular brackets $\langle>$ are to be typed as given (only the letters in BOLDFACE UPPER CASE are needed, and these may be entered in upper or lower case). Words in angular brackets are "variables" for which the user substitutes an appropriate value, again in either upper or lower case (the brackets are not typed).

If you will be communicating with the SLAC computer at 1200 BAUD or less (such as over telephone lines or with a hardcopy terminal), you will probably want to run in line-by-line mode, in which case you need to set your terminal/modem for half-duplex operation. If you will be communicating at a speed greater than 1200 BAUD, you will probably want to run in full-screen mode, in which case you need to use full-duplex, even-parity, 7-data-bit operation. You will usually connect to the computer through the "MICOM switch," which will ask you what "class" you want. If you are set up for line-by-line mode, type:

\section{VMLINE}

If you are set up for full-screen mode, type:

\section{VM24}

In full-screen mode, you will then be asked to type a carriage return, and for the kind of terminal you are using (e.g., VT100 or ADM3A). Finally, in either mode, type an extra carriage return after you see the message $\mathrm{VM} / 370$ ONLINE.

Note that in full-screen mode, whenever the screen fills up (indicated by the word MORE at the bottom), you may clear it by hitting the CLEAR key (which may be ENTER, CONTROL-L, or CONTROL-Z on your terminal); if you don't explicitly clear the screen, it will do so automatically after a minute or so (you can hold the screen indefinitely by hitting a carriage return). Also, if you are listing out information and want to abort the listing, type in HT and a carriage return before hitting the CLEAR key. In line-by-line mode, you can abort a listing with the BREAK or ATTN key.

After going through the above connection procedure, log on to the computer by typing:

$$
\begin{gathered}
\text { Logon <your-account> } \\
\text { (e.g., Logon JDOE) }
\end{gathered}
$$

Then type your password when asked for it (it will not show on your terminal), and finally type an extra carriage return after the system gives its introductory messages.

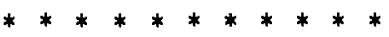

To enter the SPIRES system, type:

\section{SPIRES}

(special SPIRES-only accounts, ending in the letters SPI, don't need to do this)

To get a detailed explanation of how to use a particular SPIRES command, type:

EXPlain < command-word>

(e.g., EXPlain FIND, EXPlain EXPLAIN, EXPlain EVERYTHING) 
To get an explanation of a particular database, type:

EXPlain database-name :

(e.g., EXPlain HEP)

To access the database of interest, type:

SELect 〈database-name>

(e.g. SELeet EXPERIMENTS)

To find out what indices are available for searching in the selected database (and the various index names you may use to refer to them), type:

SHOw INDex

To see a random selection of values in an index (and thus determine the form to use for a search value), type:

$$
\begin{aligned}
& \text { BROwse <index-name> } \\
& \text { (e.g., from DATAGUIDE: BROwse Particle) }
\end{aligned}
$$

To see a selection of values in an index near a particular value (perhaps to see if a value in which you are interested is valid, or to see nearby values), type:

BROwse <index-name > <value >

(e.g., from DATAGUIDE: BROwse Particle UPSI)

To search for papers/sections-of-RPP/experiments satisfying certain criteria, type:

FINd $<$ index-name $>\langle$ value $>$ AND(OR) $<$ index-name $\rangle<$ value $>\ldots$

Some sample searches, drawn from the various databases indicated, are:

From HEP:

FINd Report-num SLAC-PUB-3164

FINd Author RUBBIA AND Date AFTER 1982

FINd Title HIGGS

This finds any paper with HIGGS as part of the title.

From DATAGUIDE:

FINd DETector OMEGA OR OMEGAPRIME

FINd REaction "PI- P - > PIO N" AND ECM 3 TO 4

Note that the "arrow" here is composed of two minus signs and a greater-than sign, and that energies (momenta) are always given in $\mathrm{GeV}(\mathrm{GeV} / \mathrm{c})$. Note also the quotes which are required here and in several of the following examples; for an explanation, see the discussion below on Searching Problems.

FINd REaction PI- P\#

This gets all reactions with $\pi^{-} p$ as the initial state, regardless of the final state.

FINd Particle "UPSI(9480)"

FINd Final-State-Part "CHI2(3555)" 
From PARTICLES:

FINd Part-Prop "DELTA(1232) WIDTH"

From REACTIONS:

FINd REaction "P $P-\rightarrow P$ P" AND OBServable DSIG/DT AND PLAB GT 10

From EXPERIMENTS:

FINd EXPeriment-num CERN-UA-001

FINd CITation "PRL 46 (1981) 1115"

Note that the above form, with spaces but no commas between the elements, must be used.

\begin{abstract}
Searching Problems: If your search does not find any results, there are two common reasons why it may have failed spuriously. (1) You may have used an incorrect form for the value for which you were searching (e.g., an incorrect particle name). To find out the correct form, use the BROWSE command for the index you are searching (see above). Note, in particular, that in reaction and particle searches, an antiparticle name is formed by following the corresponding particle name with BAR (thus the antiproton is written as PBAR); in HEP title searches, particle names are somewhat variable in their spelling, and several forms may be used. (2) Any search value containing any of the special characters ( ) $<>=$ must be enclosed in quotes "; see the examples above.
\end{abstract}

After entering a FIND command, you will be told the number of papers, sections of RPP, or experiments satisfying the criteria given. At this point, you have several options:

(1) You may list out the information available for these results by typing:

TYPe (or TYPe PAUse if you are in line-by-line mode on a CRT terminal)

[Recall that you may abort a long listing by hitting the BREAK or ATTN key if you are in line-byline mode, or by typing HT followed by a carriage return followed by the CLEAR (ENTER, CONTROL-L, or CONTROL-Z) key if you are in full-screen mode.]

If your institution is on BITNET, you may enter

SET ACTive MY FILE

OUT CLEAR

SENDFILE MY FILE TO < your home user-id > AT < your home node >

which will transmit the results to you over BITNET.

Or (2) you may narrow the list already found (i.e., add more selection criteria) by typing:

AND <index-name $><$ value $>$

Or (3) you may broaden the list already found (i.e., include more cases) by typing:

OR $<$ index-name $><$ value $>$

Or (4) you may initiate a new search with a new FIND command, or issue any other command.

To terminate the session and log of the computer, type:

CP LOGoff 


\section{Some Examples of Database Use}

We show below a short example session for each of the five databases. The boldface phrases are those typed in by the user; we show the fully spelled out form of the commands, although the abbreviations discussed above may be used freely. Since the databases are regularly updated, some of the queries shown may produce different results when you try them.

\section{A HEP Database Example}

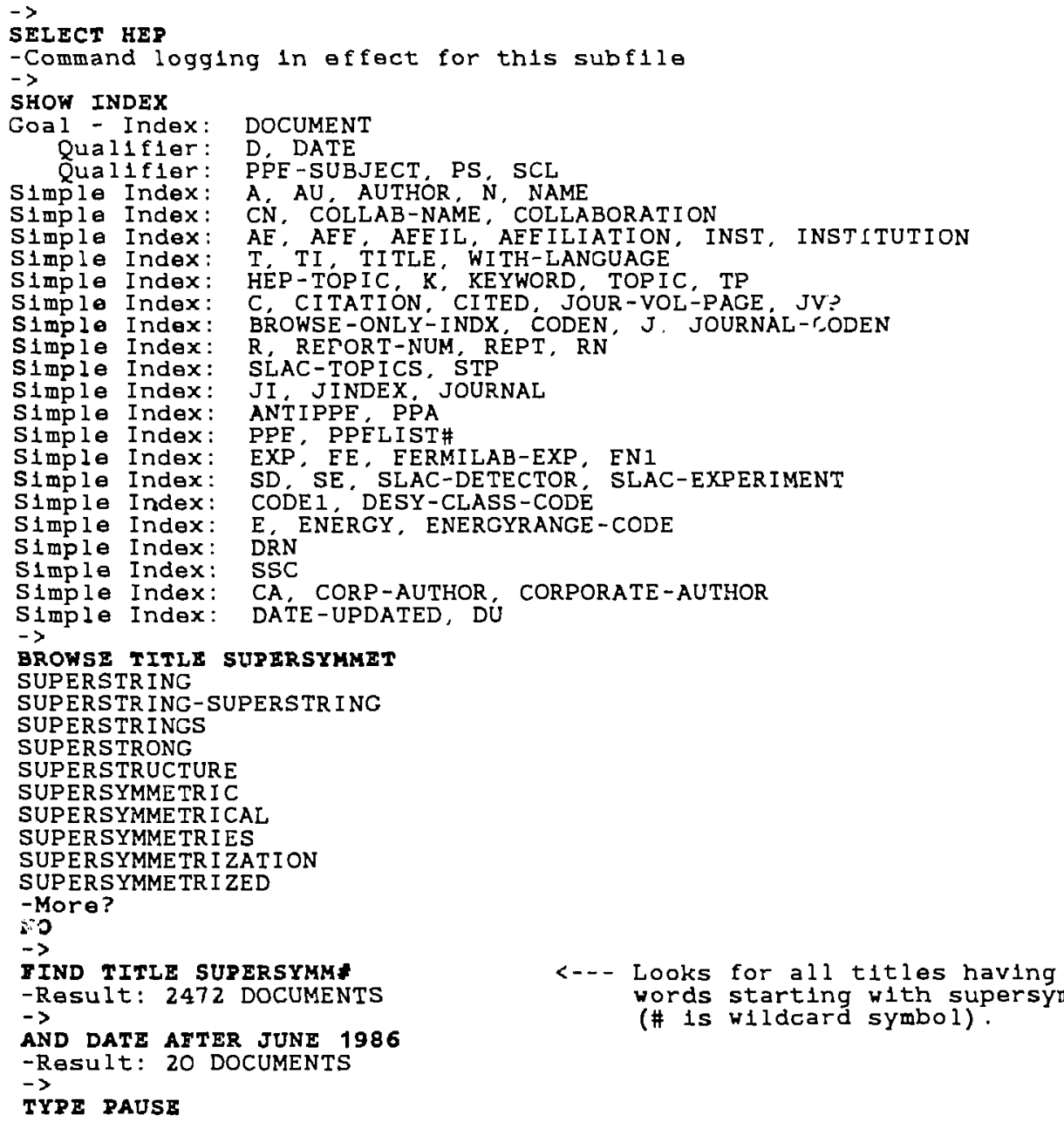

THE SEARCH EOR SUPERSYMMETRY AT THE TEVATRON AND SSC. By R.Michael Barnett (LBL, Berkeley). Howard E. Haber (UC. Santa Cruz \& SLAC), LBL-21947, Aug 1986. 11Pp. Invited talk given at Physics Simulations at High Energy Workshop. Madison, WI. MaY 5-16, 1986.

SEARCH EOR SINGLE ELECTRONS FROM SUPERSYMMETRIC PARTICLE PRODUCTION. By E. Fernandez, W.T. Ford, N. Q1, A.L. Read, Jr., J.G. Smith 


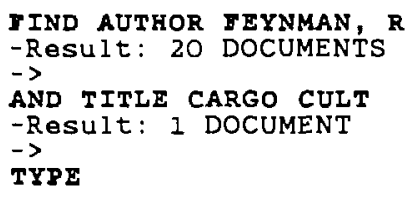

CARGO CULT SCIENCE.

By Richard P. Eeynman, RX-723, n.d. (recd Sep 1975) 4pp.
Published in Englneering and Science, p. 10-13, June 1974 (reprint).

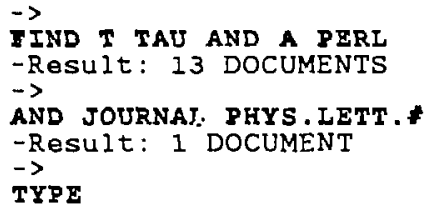

PROPERTIES OE THE PROPOSED taU CHARGED LEPTCN

By Martin L. Perl, G.J. Eeldman, G.S. Abrams, M.S. Alam, Adam M. Boyarsk1. Martin Breidenbach. J. Dorfan. Wililam Chinowsky, G. Goldhaber, G. Hanson, J. Jaros, J.A. Kadyk, D. Luke, V. Luth, R. Madaras, H.K. Nguyen, J.M. Paterson, I. Peruzz1, M. Piccolo, T. Pun

Petros A. Rap1dis, Burton Richter, W.M. Tanenbaum, J. Wiss (SLAC \&

LBL, Berkeley U UC, Berkeley), SLAC-PUB-1997, Aug 1977. 14pp.

Pubilshed in Phys. Lett.70B:487, 1977.

$->$

BROWSE CODEN PHYSICS LETTERS

PHYSICAL REVIEW (PHRVA)

PHYSICAL REVIEW LETTERS (PRLTA)

PHYSICS (PYCSA)

PHYSICS EDUCATION (PHEDA)

PHYSICS IN MEDICINE AND BIOLOGY (PHMBA)

PHYSICS LETTERS (PHLTA)

PHYSICS OE ELUIDS (PELDA)

PHYSICS REPORTS (PRPLC)

PHYSICS REPORTS SECTION C OE PHYS.LETTERS) (PRPLC)

PHYSICS TODAY (PHTOA)

-More?

No

$\rightarrow$

IIND CITATION PHLTA, 70B, 487

-Result: 60 DOCUMENTS

$\rightarrow$

BROWSE COLLABORATION CELLO

CCERR NEUTR INO COLLABORATION

CCHK COLLABORATION

CCHKK AND ACCDHW COLLABORATIONS

CCOR COLLABORATION

CDE COLLABORATION

CELLO COLLABORATION

CERN MUON STORAGE RING COLLABORATION

CERN SOVIET COLLABORATION

CERN-ANNECY (LAPP) -GENOA-COPENHAGEN-OSLO-UNIVERSITY COLL . (LONDON) COLLABORATION -More?

No

$\rightarrow$

YIND CN CELLOF

-Result: 40 DOCUMENTS

$\rightarrow$

TYPE PAUSE

A SEARCH EOR SINGLE PHOTONS AT PETRA.

By CELLO Collaboration (H.J. Behrend, et al.), LAL-86/11, n.d. (recd Jun 1986) 17pp.

Submitted to Phys. Lett. 


\section{A DATAGUIDE Database Example}

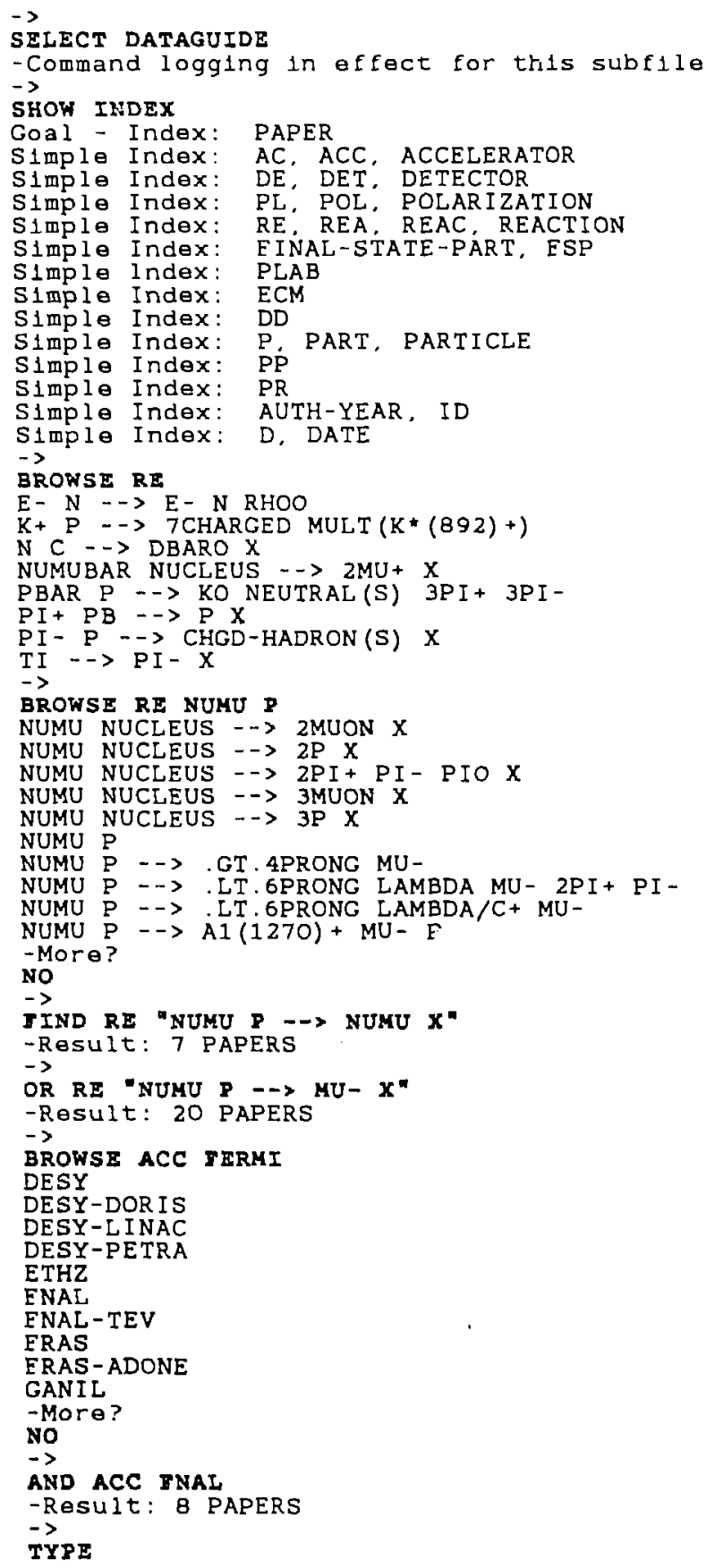

- Command logging in effect for this subfile THE ANTI-NEUTRINNO $n$ AND ANTI-NEUTRINO $p$ INTERACTIONS IN NEON NUCLEUS: TOTAL CROSS-SECTION RATIO AND QUARK - PARTON ANALYSIS.

By A.E. Asratian, V.I. E fremenko, A.V. Eedotov, P.A. Gorichev, G.K.

Kilger, V.Z. Kolganov, S.P. Kruchinin, M.A. Kubantsev, I.V.

Maklyueva, V.I. Shekelian, V.G. Shevchenko (Moscow, ITEP), V.V.

Ammosov, V.S. Burtovoy, A.G. Denlsov, G.S. Gaplenko, V.A. Gaplenko. V.I. Klyukhin, V.I. Koreshev, P.V. Pitukhin, V.I. Sirotenko, E.A. Siobodyuk, Z.U. Usubov, V.G. Zaets (Serpukhov, IEVE), ITEP-187-1984, 1984. $47 \mathrm{pp}$.

Moscow Inst. Theor. Exp. Phys. Gkae - ITEE-84-187 (84, REC.MAR.85) 47p. 
〈ACCELERATOR> FNAT, 〈DETECTOR> HLBC-15FT-HYB

$\begin{array}{lll}\text { CREACTIONS STUDIED> } & \text { ECM (GEV) } & \text { PLAB (GEV/C) } \\ \text { NUMUBAR N } \rightarrow \text { MU+ } X & 4.436-19.41 & 10-200 \\ \text { NUMUBAR P } \rightarrow \text { MU+ } \mathrm{X} & 4.432-19.40 & 10-200 \\ \text { NUMU N }->\text { MU }-\mathrm{X} & 4.436-19.41 & 10-200 \\ \text { NUMU P } \rightarrow \text { MU }-\mathrm{X} & 4.432-19.40 & 10-200\end{array}$

〈EXPERIMENTAL COMMENTS> 6774 ANUMU NE INTERACTIONS, WIDE BAND BEAM 〈E>=35 GEV

NEUTRAL CURRENTS IN THE ANTI-NEUTRINO EXPERIMENT AT THE 15-FOOT BUBBLE CHAMBER.

(In Russian)

BY P.A. Gorlchev, V.I. Efremenko, G.K. Kliger, V.Z. Kolganov, S.P.

Kruchinin, M.A. Kubátisev, I.V. Makhlyueva, A.V. Fedotov, V.G.

Shevchenko, V.I. Shekellan, V.V. Ammosov, V.A. Gaplenko, G.S.

Gaplenko. A.G. Dentsov, V.G. Zaets. V.I. Klyukh1n. V.I. Koreshev,

P.V. Pitukhin, V.I. Sirotenko, E.A. Siobodyuk, Z.U. Úsubov. J.P.'

Berge, D. Bogert, J. Malko, F.A. Nezrick, R. Orava, R. Hanft, J.

Bel1. C.T. Coffín, V. Law1s. B.P. Roy. D. Sinclair (Moscow. ITEP \&

Serpukhov, IFVE \& Eermilab \& Michigan'U.). ITEP-72-1983-mC (microfiche). 1983.

32pp.

Published in Sov.J.Nucl. Phys.39:396,1984.

〈ACCELERATOR> ENAL 〈DETECTOR> HBC-15ET

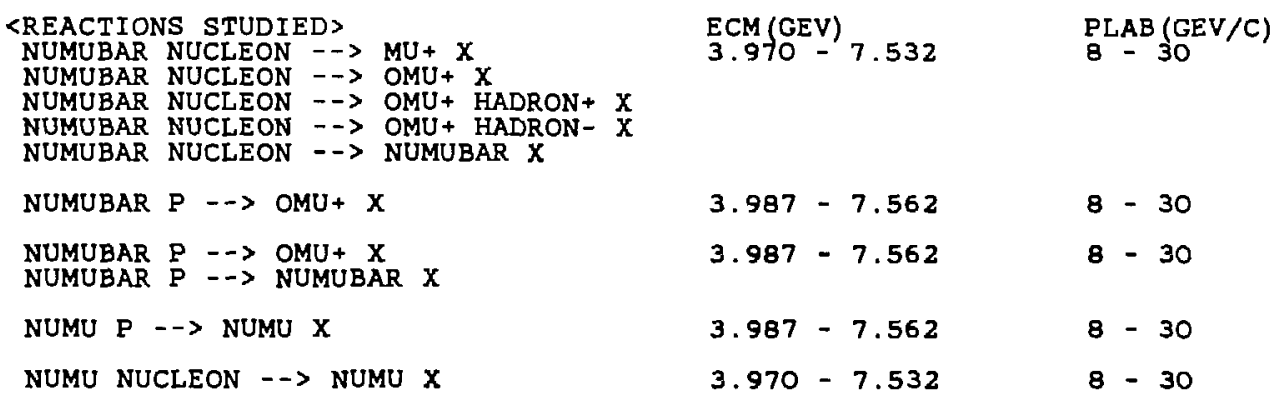

〈EXPERIMENTAL CUN MENTS> WIDE ANUMU BEAM

〈DATA COMMENTS> 2039 EVNTS

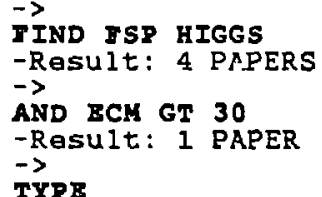

SEARCH FOR CHARGED HIGGS AND TECHNIPIONS AT PETRA.

By TASSO Collaboration (M, Althoff, et al.), DESY 82/069, Oct 1982. 21pp. Published in Phys. Latt.122B:95,1983.

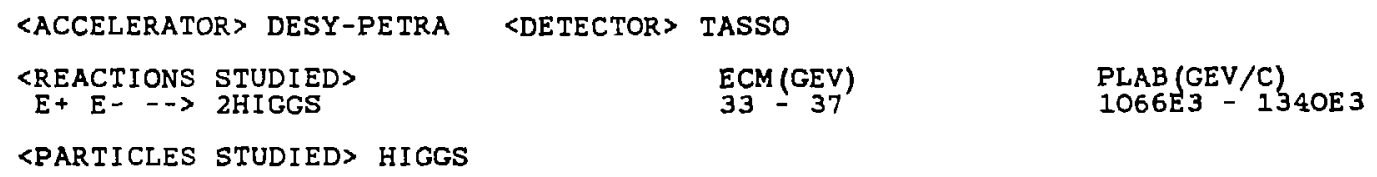




\section{A PARTICLES Database Example}

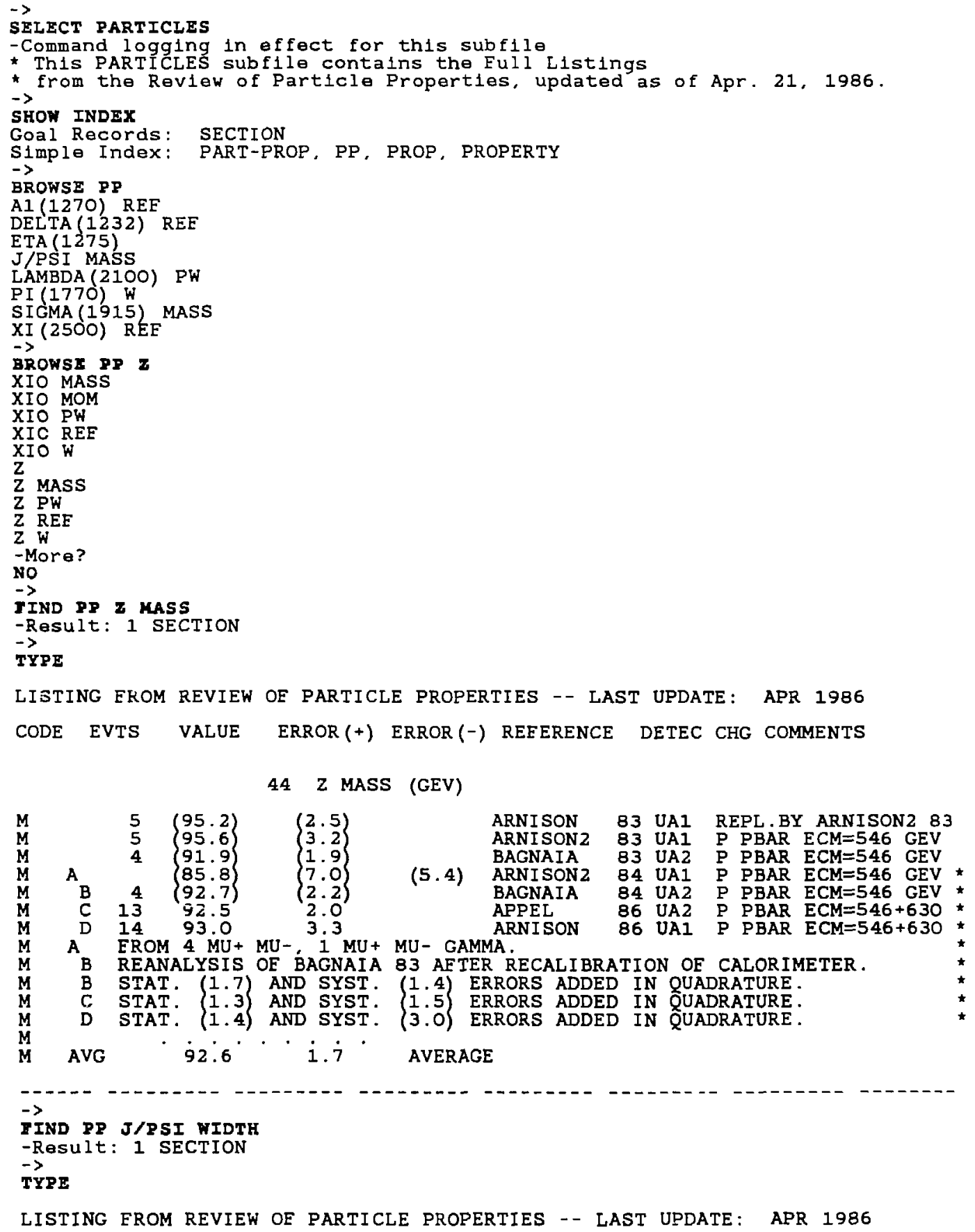


CODE EVTS VALUe ERRUR $(+)$ ERROR $(-)$ REFERENCE DETEC CHG COMMENTS $70 \mathrm{~J} /$ PSI (3097) WIDTH (KEV)

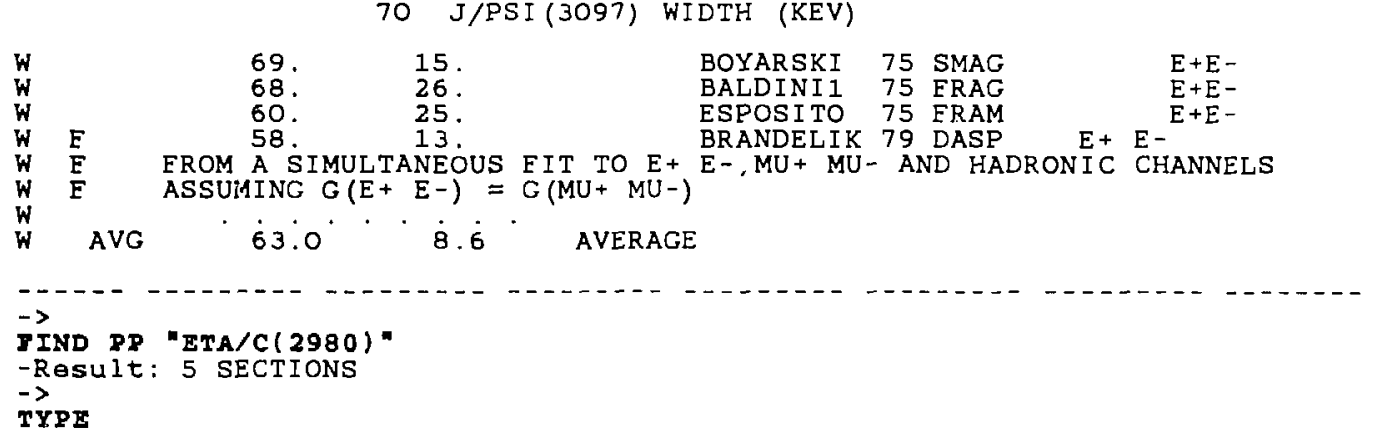

LISTING FROM REVIEW OF PARTICLE PROPERTIES -- LAST UPDATE: APR 1986 CODE EVTS VALUE ERROR(+) ERROR(-) REEERENCE DETEC CHG COMMENTS 26 ETA $/ C(2980 . J P G=0-+) \quad I=0$

OBSERVED IN THE INCLUSIVE GAMMA SPECTRUM CENERATED FROM PSI ( 3685 ) DECAY, THEREFORE C=+. FROM THE 4PI DECAY $G=+$. THEREFORE I $=0$. FROM ANGULAR DISTRIBUTION IN J/PSI TO ETA/C, ETA/C TÜ PHI PHI, JP=O- (BALTRUSAITIS 84).

26 ETA/C (2980) MASS (MEV)

\begin{tabular}{|c|c|c|c|c|c|}
\hline $\begin{array}{ll}M & M \\
M & M \\
M & B \\
M & A\end{array}$ & 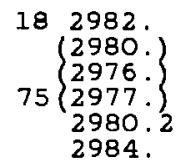 & $\left\{\begin{array}{c}8 . \\
9: \\
4: \\
1.6 \\
5\end{array}\right.$ & $\begin{array}{l}\text { HIMEL } \\
\text { PARTRIDGE } \\
\text { BALTRUSAI } \\
\text { BALTRUSAI } \\
\text { BALTRUSAI } \\
\text { GAISER }\end{array}$ & $\begin{array}{ll}80 & \text { SMK2 } \\
80 & \text { CBAL } \\
84 & \text { SMK3 } \\
85 & \text { SMK } 3 \\
85 & \text { SMK3 } \\
85 & \text { CBAL }\end{array}$ & $\begin{array}{l}\text { E+ E- } \\
\text { E }+ \text { E- } \\
\text { J/PSI, } 2 \text { PHI GAM } \\
\text { J/PSI,ETA 2PI G * } \\
\text { J/PSI,ETAC GAMMA* } \\
\text { J/PSI, GAMMA X * * }\end{array}$ \\
\hline
\end{tabular}

AVG $\quad 2980^{\circ} \cdot 6^{\circ} \cdot \dot{i} \dot{5}^{\cdot}$ AVERAGE

$M \quad M \quad M A S S$ ADJUSTED BY US TO CORRESPOND TO J/PSI (3097) MASS $=3097$.

$\begin{array}{lll}M & \text { B } & \text { ETA/C TO PHI PHI } \\ M & \text { A } & \text { AVERAGE OE SEVERAL DECAY MODES. }\end{array}$

26 ETA/C (2980) PARTIAL DECAY MODES

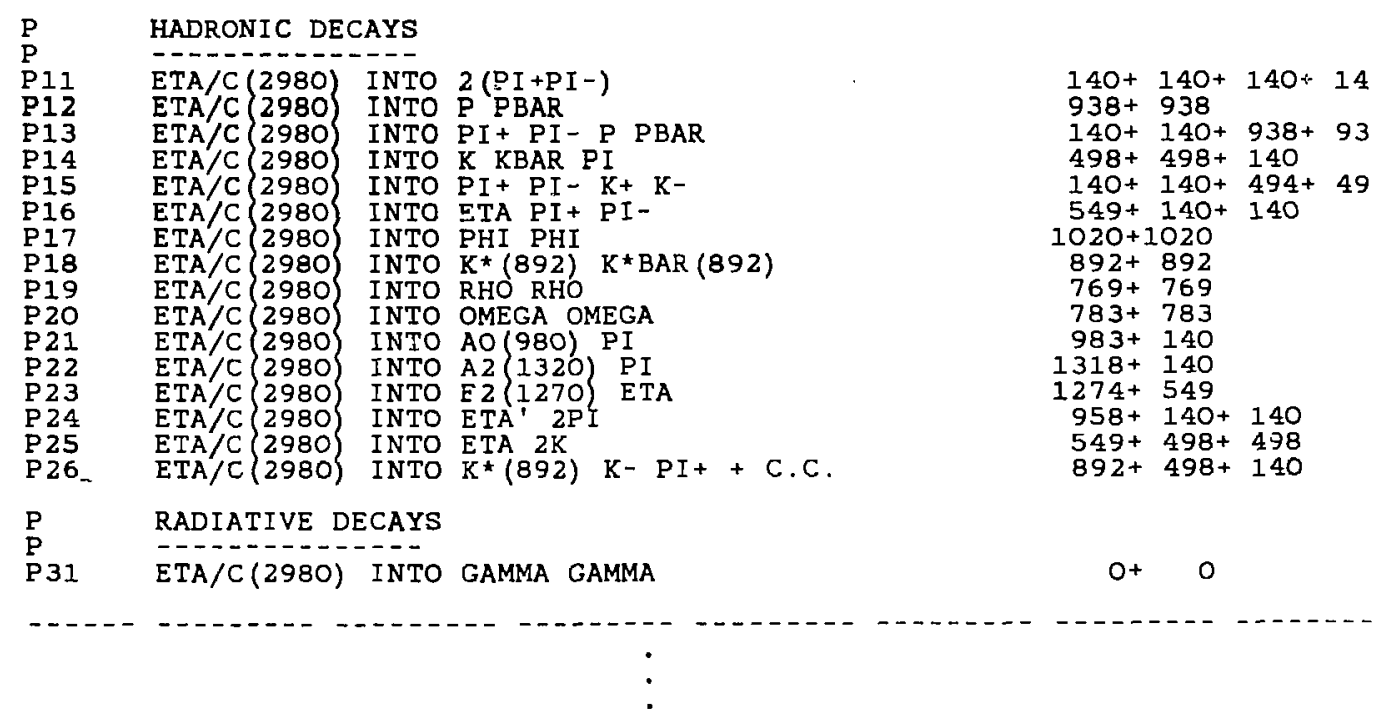




\section{A REACTIONS Database Example}

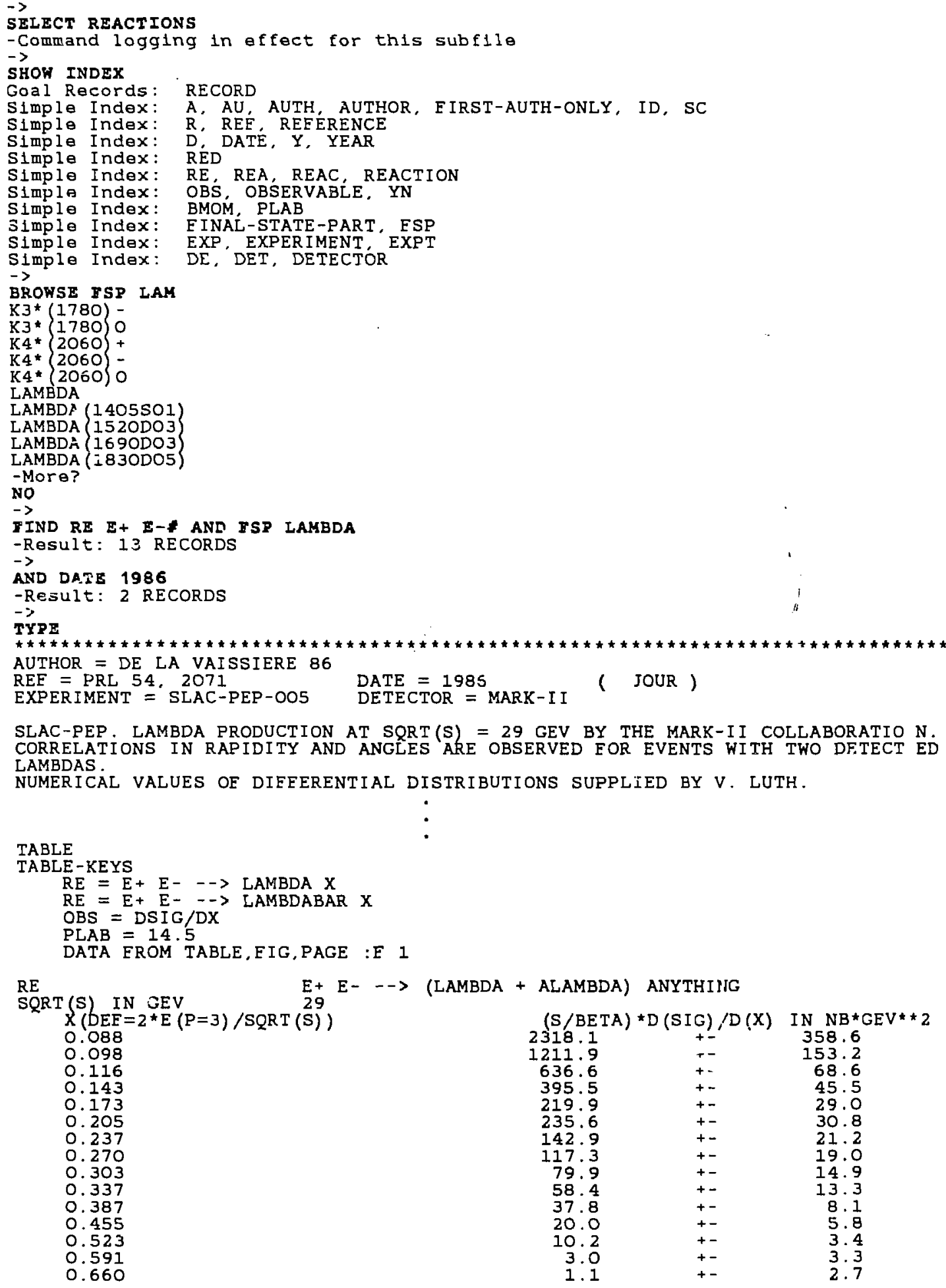

SLAC-PEP . LAMBDA PRODUCTION AT SORT (S) = 29 GEV BY THE MARK-I I COLLABORATIO N CORRELATIONS IN RAPIDITY AND ANGLES ARE OBSERVED FOR EVENTS WITH TWO DETECT ED LAMBDAS.

NUMERICAL VALUES OE DIEEERENTIAL DISTRIBUTIONS SUPPLIED BY $V$. LUTH.

TABLE

TABLE-KEYS

$R E=E+E--\rightarrow$ LAMBDA X

$R E=E+E-\rightarrow$ LAMBDABAR $X$

$O B S=D S I G / D X$

$\mathrm{PLAB}=14.5$

DATA FROM TABLE,EIG, PAGE :E 1

RE

SQRT $(S) I N$ SEV
O $($ DEE $=2 \star E(P=3) / S O R T(S))$
0.088
0.098
0.116
0.143
0.173
0.205
0.237
0.270
0.303
0.337
0.387
0.455
0.523
0.591
0.660

$E+E-\rightarrow$ (LAMBDA + ALAMBDA) ANYTHING

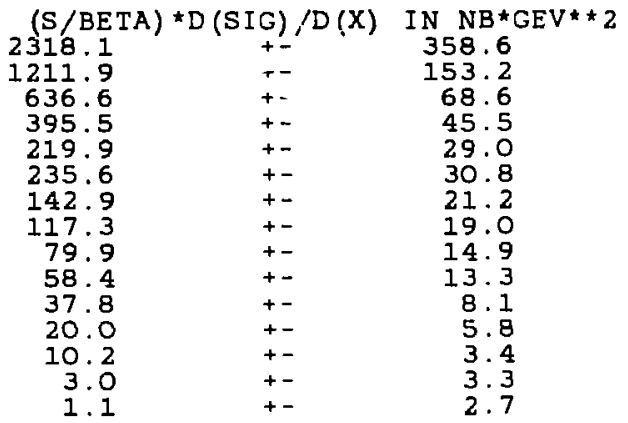




\section{An EXPERIMENTS Database Example}

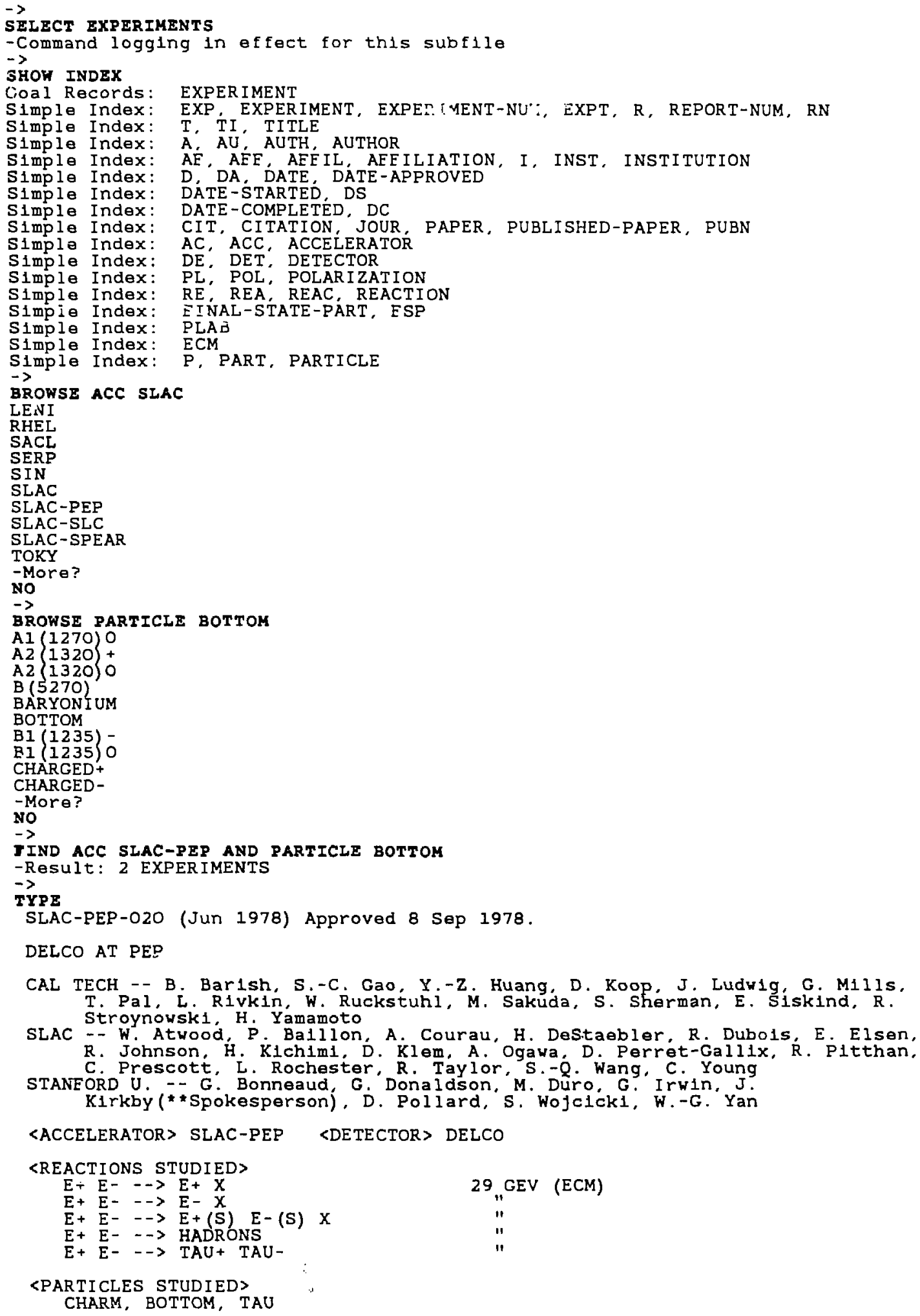




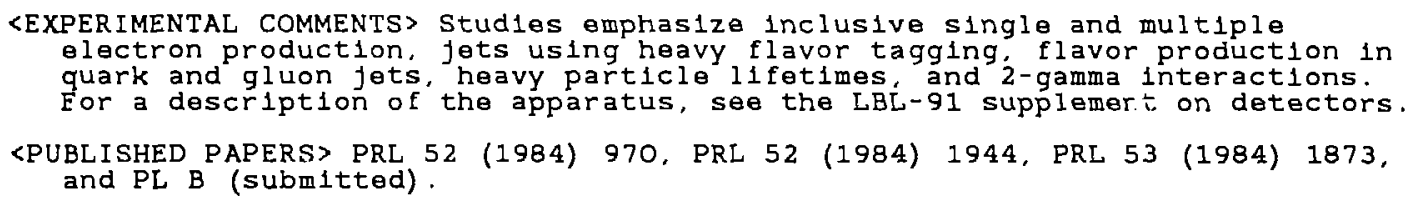

\section{Availability of Databases Elsewhere}

Several of the databases described above are accessible (under different systems) on computers in the UK (contact Dr. M. Whalley, Dept. of Physics, Univ, of Durham. South Road, Durham DH1 3LE, England; phone 0385-64971, x591) and in the USSR (contact Dr. V.V. Ezhela, Inst. for High Energy Physics, Serpukhov, Moscow Region, USSR).

\section{Acknowledgments}

Many people have been involved over the years in creating and maintaining the databases descr:bed in this report, and we are grateful to all of them. Among those involved most heavily in recent years are the encoders and secretaries of the Berkeley Particle Data Group; the SLAC library staff; Dr. V.V. Ezhela and the staff of the USSR COMPAS group; Dr. F.D. Gault, Dr. B.J. Read, Dr. R.G. Roberts, and the staff of the UK Particle Data Group; and Dr. H. Schmidt and the DESY High Energy Physics Index staff.

\section{References}

1) Particle Data Group, "A Guide to Data in Elementary Particle Physics," LBL-90 (available fall 1986).

2) C.G. Wohl et al. (Particle Data Group), "Review of Particle Properties," Phys. Lett. 170B (April 1986).

3) C.G. Wohl et al. (Particle Data Group), "Current Experiments in Elementary Particle Physics," LBL-91 Revised (January 1985). 
This report was done with support from the Department of Energy. Any conclusions or opinions expressed in this report represent solely those of the author(s) and not necessarily those of The Regents of the University of California, the Lawrence Berkeley Laboratory or the Department of Energy.

Reference to a company or product name does not imply approval or recommendation of the product by the University of California or the U.S. Department of Energy to the exclusion of others that may be suitable. 